\title{
Performando a história de uma política pública à luz da
} ANTi-History

Mariana Maia Bezerra ${ }^{1}$

Ana Silvia Rocha Ipiranga 2

1 Faculdade de Ciências e Tecnologia do Nordeste, Fortaleza / CE - Brasil

2 Universidade Estadual do Ceará / Programa de Pós-Graduação em Administração, Fortaleza / CE - Brasil

Tendo como base construtos da abordagem da ANTi-History, o objetivo do estudo foi (re)montar as múltiplas versões históricas que performaram no tempo e no espaço o organizar artístico do Salão de Abril. O Salão de Abril é atualmente uma das principais políticas públicas direcionadas ao meio artístico da cidade de Fortaleza, contando com mais de 70 anos de existência. A metodologia de caráter histórico teve como fonte o levantamento de documentos e a compilação do arquivo da pesquisa. Na análise da escrita historiográfica foram identificadas 4 passagens históricas que evidenciaram as associações de diferentes atores em rede. Ressaltou-se o caráter político do organizar do Salão de Abril, ao apresentar alternativas das versões de um passado que reverbera, hoje, nas relações com os espaços da cidade e nos mecanismos de políticas públicas.

Palavras-chave: ANTi-History; organização artística; salão de abril; política pública.

\section{Interpretando la historia de una política pública a la luz de la antihistoria}

A partir de constructos del enfoque antihistoria, el objetivo del estudio fue (re)ensamblar las múltiples versiones históricas que actuaron en el tiempo y el espacio en la organización artística del Salón de Abril. El Salón de Abril es en la actualidad una de las principales políticas públicas orientadas al entorno artístico de la ciudad de Fortaleza, con más de 70 años de existencia. La metodología histórica se basó en la recolección de documentos y la compilación del archivo de investigación. En el análisis de la escritura historiográfica se identificaron 4 pasajes históricos que evidenciaron las asociaciones de diferentes actores de la red. Se enfatizó el carácter político de la organización del Salón de Abril, al presentar alternativas de las versiones de un pasado que reverbera, hoy, en las relaciones con los espacios de la ciudad y en los mecanismos de políticas públicas.

Palabras clave: antihistoria; organización artística; salón de abril; políticas públicas.

\section{Performing the history of public policy in the light of ANTi-History}

This study is based on constructs of the ANTi-History approach. It aims to (re)assemble the multiple historical versions that performed in time and space in the artistic organization of Salão de Abril, an art exhibition in the municipality of Fortaleza, Brazil. Salão de Abril is currently one of the main local public policies for arts, with more than 70 years of existence. The historical methodology was based on the collection of documents and the compilation of the research archive. In the analysis of historiographical writing, the study identified four historical passages showing associations of different actors in a network. The political character of the exhibition's organization was emphasized when presenting alternatives for the versions of a past that reverberate, today, in the relations with the spaces of the city and in the public policies mechanisms.

Keywords: ANTi-History; arts organization; Salão de Abril; public policy. 


\section{AGRADECIMENTOS}

As autoras agradecem ao Conselho Nacional de Desenvolvimento Científico e Tecnológico - CNPq.

\section{INTRODUÇÃO}

Nas últimas décadas, a aproximação entre história e estudos organizacionais (EOs) vem sendo abordada por diversos pesquisadores, desde o movimento conhecido como historic turn na administração (Clark \& Rowlinson, 2004; Kieser, 1994; Vizeu, 2010). Essa aproximação, por sua vez, abriu um diálogo entre os campos, delineando pesquisas para além do cunho universal e presentista, mais amplas e atentas à dimensão histórico-temporal e espacial (Barros, Alcadipani \& Bertero, 2018; Booth \& Rowlinson, 2006).

Nesse contexto, questionamentos sobre como fazer história na administração e nos EOs foram surgindo (Booth \& Rowlinson, 2006), articulando abordagens alternativas como a ANTi-History, baseando-se nas discussões da historiografia crítica, da sociologia do conhecimento e da teoria cultural (Durepos \& Mills, 2012). Em particular, evidenciam-se as articulações com a abordagem da Actor-Network Theory (ANT), da qual se originou a nomenclatura ANTi-History, que tem como pressuposto (re)montar um conhecimento do passado, traçando as relações entre os atores em redes (Bettin \& Mills, 2018).

Tendo em vista que as narrativas são performadas em dado momento e de maneira específica, são as relações e as associações entre os atores em rede que constroem diferentes versões históricas (Bettin \& Mills, 2018). Durepos e Mills (2017) discutiram que a história é (re)montada por meio de associações performadas na prática. Nessas interações, ou o que os autores chamaram de pontos de oscilação, traços do passado podem passar a ser histórias, as quais, por sua vez, podem passar a participar e a se integrar no conhecimento do passado, revelando múltiplas versões (Bettin \& Mills, 2018).

Conforme um mapeamento realizado nas principais bases de dados - entre estas os portais de Capes, Spell e Scopus -, constatou-se uma escassez nesta literatura de trabalhos teóricos-empíricos, sobretudo, que articulassem a ANTi-History à problemáticas da administração pública. No âmbito internacional, foram realizados estudos sobre companhias aéreas multinacionais (Deal, Mills, Mills \& Durepos, 2019; Durepos, 2009; Hartt, Mills, Mills \& Corrigan, 2014; Kivijärvi, Mills \& Mills, 2019), figuras intelectuais e feminismo (Bettin \& Mills, 2018; Durepos, Mills \& Weatherbee, 2012; Hartt et al., 2017), associações acadêmicas (Myrick, Mills \& Mills, 2013) e contabilidade e orçamento (Corrigan, 2019). Ao observarmos a esfera nacional, a escassez de estudos que utilizaram a abordagem da ANTi-History é ainda maior, tanto em termos teóricos quanto teórico-empíricos. Contudo, foi possível identificar pesquisas que enveredaram para o campo do setor público, como o trabalho de Quelha-de-Sá e Costa (2019), que realizaram uma discussão histórica sobre a constituição do Memorial da Resistência do Governo de São Paulo, além do trabalho teórico-empírico de Ipiranga, Chaym e Sousa (2016), que problematizaram o conceito do socio-past no contexto de laboratórios de pesquisa e desenvolvimento de uma instituição pública.

O presente artigo propõe a articulação do construto pontos de oscilação da ANTi-History (Durepos \& Mills, 2017) para escrutinar os processos históricos no contexto de uma organização do setor artístico: o Salão de Abril, uma das principais políticas públicas direcionada ao meio artístico da cidade de Fortaleza (Estrigas, 1994; Silva, 2013). Para além de um evento, considerou-se o Salão de Abril 
uma organização, ao enfatizarmos o ato de organizar como um fenômeno difuso, processual e aberto (Cooper, 1976), permeando aspectos criativos e culturais da cidade, ao transcender o tempo e o espaço ao qual se propôs. Para Grey, o estudo das organizações não se concentra apenas nas corporações e nas instituições; envolve diferentes facetas da vida humana e das experiências de pessoas vivendo em conjunto, discutindo, criticando, desejando, criando, resistindo, em suma, organizando. Para o autor, "todas as formas de atividades coletivas - a política, a família, bem como o trabalho - constituem, de alguma forma, uma organização" (2010).

Justifica-se a relevância desta pesquisa na medida em que compreender como as histórias dessa organização artística foram performadas pode revelar atores e narrativas históricas dominantes em relação àqueles(as) que foram silenciados (Clark \& Rowlinson, 2004; Decker, 2013; Durepos \& Mills, 2012). Pressupõe-se que esta seja uma reflexão potencialmente restauradora, base e subsídios para a formulação de políticas públicas para esse relevante setor artístico de Fortaleza.

Considerando o período entre a fundação do Salão de Abril, em 1943, e o ano de 2018, formulamos a seguinte questão: como ocorreram as múltiplas versões históricas durante os processos do organizar do Salão de Abril? O objetivo do estudo foi (re)montar as múltiplas versões históricas que performaram no tempo e no espaço o organizar artístico Salão de Abril.

\section{ANTI-HISTORY: PRINCÍPIOS E PONTOS DE OSCILAÇÃO}

Ao discorrer sobre passado e história, Bettin e Mills (2018) diferenciam os termos ao explicar que "passado é definido como o que aconteceu antes do momento presente e a história é entendida como a(s) narrativa(s), o(s) conhecimento(s) que é(são) construído(s) sobre o passado" (p. 70, tradução nossa). Com base na ANTi-History, o conhecimento do passado pode ser (re)montado com base nos traços, na política e nas convergências dos atores em rede (Durepos \& Mills, 2012). Dessa maneira, a história é construída por meio das relações entre os atores heterogêneos, explorando as atividades relacionais que produzem o conhecimento do passado (Durepos et al., 2012).

Três princípios fundamentais norteiam a ANTi-History: multiplicidade, simetria e relacionismo (Bettin \& Mills, 2018). A multiplicidade se baseia na ideia de que as diversas interpretações de fatos do passado podem levar a múltiplas histórias. Assim, a história se configura como um recurso que pode ser instrumentalizado de acordo com interesses (Rowlinson et al., 2014). Para acessar esse passado performado pela história, é necessário seguir os atores e mapear a organização de suas práticas (Bettin \& Mills, 2018; Durepos et al., 2012).

As concepções oriundas da ANTi-History que englobam partes da abordagem da ANT estão centralizadas nas ideias de que o social é constituído por atores em rede, que oscilam entre um e outro e que devem ser analisados de forma simétrica (Durepos, 2009). O princípio da simetria implica compreender que o social é formado por uma rede heterogênea de atores híbridos, humanos e não humanos, na qual não há imposta uma assimetria não genuína (Bloor, 2009; Latour, 2012; Law, 1992). A proposta da abordagem da ANTi-History é ir além da ANT ao tratar a própria história como um efeito da interação em rede (Durepos, 2009; Durepos \& Mills, 2012). Desse modo, analisar de forma simétrica implica não "encontrar a representação 'mais verdadeira' do passado, e sim explorar como diferentes narrativas históricas interagem umas com as outras, tanto quando concordam quanto quando discordam" (Bettin \& Mills, 2018, p. 71, tradução nossa).

Ao traçar as narrativas, os atores envolvidos devem ser seguidos igualmente, sem uma visão $a$ priori. A história é (re)construída por meio de interações e relações densas e não arbitrárias (Bettin 
\& Mills, 2018; Durepos \& Mills, 2012). Essa é a ideia que contempla o princípio do relacionismo, na qual se evidenciam as conexões entre os atores e a necessidade de traçar as relações entre as diferentes representações da história, compreendendo-as como um conjunto de interações heterogêneas (Durepos et al., 2012; Hartt et al., 2017).

Para a abordagem da ANTi-History, a história é formada por "uma série de relações que unem os atores (traços do passado) como rede (histórias plausíveis) e a rede como atores - histórias que participam na produção de subsequentes histórias" (Durepos \& Mills 2017, p. 58, tradução nossa). Com base nesse último princípio, Durepos e Mills (2017) desenvolvem o conceito de pontos de oscilação que representa os movimentos das narrativas, em que a atuação política se faz presente e a história toma novas facetas, sendo moldada ou transformada. Assim, faz-se necessário compreender o que acontece nesses pontos, nos quais as múltiplas versões se articulam e se manifestam. Em cada um dos pontos há um movimento de oscilação e relação, continuamente alternando e performando a história. Os autores indicam 5 pontos de oscilações: (1) passado - história, (2) ator - rede, (3) humanos - não humanos, (4) pesquisador(a) - traços do passado, (5) inscrição histórica - formação de leitura (Durepos \& Mills, 2017).

No primeiro ponto, passado - história, eles sugerem que há diferenças entre o que é passado e o que é história, tendo em vista que a história é a performance do passado. O passado e a história são ontologicamente dissonantes, haja vista que não há como reproduzir o passado. Em vez disso, reproduzimos histórias, que são versões do passado (Kivijärvi et al., 2019). Se por um lado se deve estar atento a como o passado se torna história, por outro se deve observar como a história revela e performa múltiplas versões do passado. Dessa forma, é ressaltada a importância em compreender como uma dimensão se torna a outra, alternando num movimento pendular (Durepos \& Mills, 2017).

O segundo ponto preconiza que, no alinhamento de interesses, os atores agem como um ator único. Segundo Durepos e Mills (2017), para compreender a história e como ela se inscreve, é preciso traçar as relações que mantêm a rede de atores intacta, identificando e conectando as associações que dão suporte à história como efeito dessa rede. É assim que a ANTi-History evidencia a necessidade de traçar as relações entre ator - rede, observando quando deixam de ser atores e passam a agir como uma rede, e vice-versa (Durepos et al., 2012).

O terceiro ponto relata que os atores podem ser humanos ou não humanos (Myrick et al., 2013). Baseados na ANT e na ideia de que não há humanos dissociados de não humanos, Durepos e Mills (2017) questionam o motivo de estudá-los de maneira distinta, ressaltando a importância de uma abordagem histórica que leve em conta a atuação de ambos. Reflete-se ainda a possibilidade da mobilização desses atores em configurações heterogêneas, articulando também os atores híbridos (Latour, 2012; Law, 1992). A história seria performada para além das associações entre atores humanos e não humanos; traria também a associação entre humanos - não humanos - híbridos, configurando redes heterogêneas (Durepos \& Mills, 2017).

O quarto ponto de oscilação, pesquisador(a) - traços do passado, reflete as decisões tomadas pelo(a) pesquisador(a) ao (re)montar as histórias e os privilégios de certos materiais ao serem escolhidos. Essas decisões sugerem os diversos encontros com os documentos e como esses traços são colocados como história (Schwartz \& Cook, 2002). De acordo com Durepos e Mills (2017), o quarto ponto "é o local de oscilação entre o(a) pesquisador(a) e seus traços [do passado] para ver como cada um é alterado em virtude do encontro, bem como a implicação para a inscrição histórica" (p. 63, tradução nossa). 
Por fim, o ponto inscrição histórica - formação de leitura induz à reflexão sobre as diferentes interpretações, tendo em vista que se pode "entender que formações de leitura dão vida a textos, permitindo que certas interpretações emerjam, popularizem-se e viajem ao longo do tempo" (Durepos \& Mills, 2017, p. 63, tradução nossa). Dessa forma, os textos gerarão diferentes interpretações; por isso, histórias não podem ser compreendidas como independentes, já que cada leitor é formado por experiências e contextos que o levam a um itinerário de leitura sobre uma inscrição histórica (Schwartz \& Cook, 2002).

\section{ORGANIZAÇÕES ARTÍSTICAS: CULTURA E POLÍTICAS PÚBLICAS}

Conforme exposto, neste trabalho compreendemos a ideia da organização para além dos muros (Strati, 1995), sejam corporativos e ou institucionais, como fenômeno difuso, processual e aberto (Cooper, 1976), constituída por grupos de pessoas que atuam coletivamente (Durepos \& Mills, 2012; Grey, 2010). Alguns trabalhos que abordaram as organizações artísticas permearam os setores criativos e a produção de bens culturais (Reis, 2007; Rentschler \& Potter, 1996), ao passo que outros utilizaram o termo associado às organizações culturais (Hoffmann, Silva \& Dellagnelo, 2009) ou como sinônimo (D’Astous, Colbert \& Fournier, 2007; Flach \& Antonello, 2011). Para Flach e Antonello (2011), essas organizações estão situadas no âmbito artístico e cultural, com a característica essencial de não produzir em massa. Já D’astous et al. (2007) associam o termo à produção cultural e a contextos do setor público, exemplificando essas organizações por meio de museus, teatros e orquestras.

Nesse contexto, é interessante destacar que a cultura de uma cidade também se destaca como fonte essencial à construção da identidade cultural das pessoas que habitam os espaços urbanos e dos coletivos que elas constituem (Ipiranga, 2010). Vieira, Knopp e Costa (2011) ainda destacaram que, de forma prática, essa articulação ocorre e se evidencia pela implementação de políticas, programas e projetos permeados por mecanismos de seleção e da gestão pública. Os editais públicos de indução, por exemplo, ampliam e diversificam as iniciativas culturais na medida em que determinam incentivos para as mais diversas organizações artísticas, muitas vezes não sendo suficientes para manter essas articulações estáveis (Gadelha \& Barbalho, 2017).

Hoffmann et al. (2009) ao observarem que a ausência de recursos influencia no modo como as organizações artísticas se comportam, ressaltaram a importância das discussões acerca das políticas públicas, do papel do Estado e da participação do setor privado nessas redes. Muitas vezes, essas redes de relações tomam diferentes configurações ao longo do tempo, e é nesse sentido que as discussões sobre tais governanças se direcionam para os avanços da produção cultural e artística do país.

Ao debater a importância do fomento público, Medeiros (2012) destaca a necessidade de continuidade de políticas públicas que apoiam o meio artístico cultural em geral. Segundo Subirats, Knoepfel, Larrue e Varone (2008, p. 33, tradução nossa), as políticas públicas representam "a resposta do sistema político-administrativo a uma situação de realidade social considerada politicamente inaceitável". Os resultados desejados dessa resposta dependem de uma complexa interação entre os diversos grupos de atores envolvidos, suas decisões e interesses negociados (Hoffmann et al., 2009; Subirats et al., 2008).

Nesse contexto, Medeiros (2012) ressalta que, sendo o Salão de Abril uma das principais políticas de incentivo às artes na cidade de Fortaleza, é necessário rever sua configuração. Diante disso, indaga-se: como rever essa configuração e/ou adotar uma nova? Como as narrativas históricas de tempos passados 
relativas ao organizar artístico do Salão de Abril foram criadas, performadas, mantidas e transformadas desde 1943? As reflexões sobre a história desse organizar artístico, que permeiam aspectos políticos e culturais, poderão reverberar nas políticas públicas dos setores envolvidos.

\section{PROCEDIMENTOS METODOLÓGICOS}

Um dos principais espaços de fomento público às artes da cidade de Fortaleza, o Salão de Abril conta atualmente com mais de 70 anos de existência, tendo sido pontuado como "o principal evento de Artes Plásticas do Ceará e um dos mais prestigiados e concorridos do país" pelo então prefeito Roberto Cláudio (Prefeitura de Fortaleza, 2018, p. 4).

Criado em 1943, o Salão de Abril não só é considerado um espaço no qual os artistas podem apresentar suas criações, mas também um marco histórico de resistência para o meio cultural e artístico da cidade de Fortaleza. Assim, revelar como suas histórias foram contadas e performadas pode externar atores e narrativas dominantes em relação àqueles(as) que foram silenciado(a)s (Clark \& Rowlinson, 2004; Decker, 2013; Durepos \& Mills, 2012). Dessa forma, para esta pesquisa, pressupõe-se que tais histórias podem articular uma reflexão potencialmente restauradora, base para a formulação de políticas públicas para esse setor artístico de Fortaleza.

Partindo do objetivo proposto, realizamos uma pesquisa de caráter histórico, fundamentada nos princípios da ANTi-History (Bettin \& Mills, 2018). Nosso primeiro contato com o Salão de Abril ocorreu em 2017, na organização denominada Salão de Abril "Sequestrado" (Bezerra, Sousa, Silva \& Ipiranga, 2019). No decorrer de nossas pesquisas sobre a organização desse salão de 2017, alguns materiais nos levaram à história do Salão de Abril, entre eles os livros e os trabalhos do historiador e artista Estrigas, o Minimuseu Firmeza e seu arquivo histórico, além das histórias que sobressaiam dos relatos dos atores organizadores desse salão. Diante dessas possibilidades de construção de uma história, buscamos ir além da história a priori (Durepos \& Mills, 2012; Hartt et al., 2017) para compreender como esses relatos foram se constituindo desde 1943, ano de fundação do Salão de Abril, até 2018, data de início desta pesquisa.

Num primeiro momento, foram realizados o mapeamento e a compilação de documentos em diferentes arquivos, visando à construção do acervo da presente pesquisa (Barros, 2016). Iniciamos a busca pelos livros de Estriga, artista conhecido por seus estudos sobre a história do Salão de Abril. Em seguida, coletamos materiais on-line em diferentes sites, potencializando a pesquisa histórica (Barros, 2016) - por exemplo, realizamos o levantamento de 60 catálogos que narravam a organização de diferentes edições do Salão de Abril, com mapeamento dos espaços e das redes de artistas participantes. Além disso, individualizamos uma tese de doutorado, duas dissertações de mestrado e diversos artigos publicados em periódicos sobre o Salão de Abril de diferentes áreas do conhecimento.

Sabendo que os arquivos como lugar e conjunto de documentos, ou a ausência deles, podem demonstrar relações de dominação e poder, criando ou silenciando narrativas (Decker, 2013; Schwartz \& Cook, 2002), procuramos seguir diferentes rotas de buscas durante a construção desse acervo, visitando diferentes espaços, públicos e privados, como arquivos, bibliotecas e museus. Uma seleção prévia desses lugares e arquivos se deu por meio de uma pesquisa anterior sobre o Salão de Abril realizada por Silva (2013). Além disso, ao longo da interação com o campo, escrevemos um diário no qual descrevíamos esses lugares e os processos cotidianos da pesquisa, além das reflexões e dos anseios da primeira autora dessa pesquisa. Ao nos defrontarmos com o vasto número de materiais 
e documentos, ressaltamos que alguns foram escolhidos em detrimento de outros. Outros(as) pesquisadores(as) poderiam seguir caminhos e montar uma coleção diferentes. Dessa forma, não poderemos ignorar o nosso papel durante a pesquisa, o que permeia os pontos de oscilação do(a) pesquisador(a) e traços do passado da ANTi-History (Durepos \& Mills, 2017).

Após finalizarmos o levantamento, assim como as reflexões sobre a construção do acervo da presente pesquisa, seguimos para a fase de organização e análise do material, que se deu em duas etapas. A primeira, efetuada junto com o levantamento, consistiu em identificar, selecionar e agrupar o material. Numa segunda etapa, seguiu-se o procedimento de análises, por meio de leitura superficial, seletiva e atenta, segundo Barros et al. (2018). As leituras seletiva e atenta foram apoiadas pelo uso do software de análise Maxqda (2018). Dessa forma, e com base no objetivo dessa pesquisa, seguimos os atores e mapeamos suas redes na (re)construção dos eventos, em diferentes etapas históricas, codificando-os por meio do software. A partir disso, descrevemos por meio de uma escrita historiográfica as múltiplas versões históricas do organizar artístico da política pública Salão de Abril (Durepos \& Mills, 2012).

\section{PERFORMANDO AS HISTÓRIAS DO ORGANIZAR ARTÍSTICO DA POLÍTICA PÚBLICA SALÃO DE ABRIL}

Considerando o período de 1943-2018 e baseado no primeiro ponto de oscilação que sugere a importância de compreender, num movimento pendular, como o passado se torna história (Kivijärvi et al., 2019), descreveremos a seguir as 4 passagens históricas reveladas durante a análise e que influenciaram as (re)montagens das redes de atores e suas múltiplas versões do Salão de Abril: o Salão da União Estadual dos Estudantes (UEE), o Salão da Sociedade Cearense de Artes Plásticas (Scap), o Salão (Municipal) da Prefeitura e o Salão de Abril Sequestrado.

No último item desta análise, discutiremos como esse conhecimento do passado foi (re)montado, evidenciando que as redes de atores identificadas nas diferentes passagens históricas se interpolavam, oscilando e performando as passagens de forma não sequencial e não cronológica, indicando tempos e espaços distintos e simultâneos que atuam no organizar do Salão de Abril até os dias de hoje (Durepos \& Mills, 2012; Myrick et al., 2013).

\subsection{A História do Organizar do Salão da UEE}

O Salão de Abril surgiu em 1943 sob liderança da UEE, sendo esta considerada a célula mãe da organização artística (Exposição de Arte, 1943; Estrigas, 1994). A entidade universitária tinha sua diretoria formada por acadêmicos de diferentes escolas superiores, além de fazer diversas aparições em matérias de jornais organizando eventos, festas, passeatas e manifestações de cunho político (Leite, 1949).

Associada à entidade estudantil, por trás da ideia de proposição do salão, estão alguns atores humanos que emergiram no decorrer de inscrições históricas, entre eles 3 acadêmicos que, juntos, formavam o que Estrigas (1983) denominou de Santíssima Trindade: Aluízio Medeiros, secretário de arte da UEE; Antônio Girão Barroso, diretor da UEE e criador do nome Salão de Abril; e Raimundo Ivan de Oliveira, presidente da UEE. As narrativas, ao destacarem essa rede de atores heterogêneos 
que caracterizou a entidade UEE, possibilitaram construir inferências sobre o início do processo do organizar do Salão, relevando que as tramas históricas construíram mais de uma versão do passado (Bettin \& Mills, 2018; Durepos \& Mills, 2017), conforme trecho de um dos catálogos:

Por um desvio de informação tem sido consignado a Raimundo Ivan de Oliveira o posto de presidente, quando na realidade, o eleito e ocupante do mesmo foi o acadêmico de agronomia Gilson Leite Gondim. Raimundo Ivan foi seu orador. Aqui fica a retificação desse pequeno desvio, recolocando a verdade histórica no seu devido lugar (Prefeitura de Fortaleza, 1996, p. 5).

Essa versão histórica indicando outro ator como presidente da UEE atuou na produção de histórias subsequentes (Durepos \& Mills 2017) ao ressurgir nos catálogos dos anos 1997 e 2000. Ainda no catálogo de 2002, o nome de Raimundo Ivan de Oliveira é retomado, e Gilson Leite mais uma vez se torna um ator ausente no organizar do Salão de Abril. As alternâncias desses atores em relação à presidência da UEE vinham sendo citadas e/ou silenciadas nos diferentes traços do passado e por diversos anos entre as passagens históricas analisadas, denotando (re)montagens dos atores em rede de forma não cronológica.

No que tange à data selecionada para a realização do salão em 19 de abril, há um ator associado que também não se faz presente nos relatos históricos predominantes dos catálogos, evidenciando narrativas paralelas em tempos distintos (Clark \& Rowlinson, 2004; Decker, 2013). Os jornais que coletamos da década de 1940 apresentam o Salão de Abril como parte das comemorações do aniversário do presidente à época, Getúlio Vargas. Ao seguirmos essa sinuosa trajetória do salão e tomando os relatos jornalísticos de 1943, as inscrições históricas de sua organização enfatizam o adjetivo "festivamente" ao se referir ao aniversário de Getúlio Vargas em 1943. Salientamos aqui a oscilação de uma versão do passado que advém da associação entre atores humanos e um ator não humano, os jornais da época, refletindo contraditórias mobilizações desses atores em configurações heterogêneas. Essas mobilizações contraditórias entre os atores em redes foram inferidas com base em alguns trechos de relatos que minimizaram a ênfase festiva ao narrar que os estudantes da UEE organizaram o salão como forma de apresentar a sociedade cearense, seus artistas e o movimento artístico cultural da cidade, sem mencionar como justificativa o fato de ter ocorrido em 19 de abril, aniversário de Getúlio Vargas (Estrigas, 1983; Prefeitura de Fortaleza, 1970). Relevamos processos interativos contraditórios que trouxeram o passado em movimentos pendulares, caracterizados por narrativas simétricas sobrepostas de versões históricas sobre o organizar do Salão da UEE, que teve apenas um ano de existência (Bloor, 2009; Latour, 2012; Law, 1992). O segundo Salão de Abril só viria a ser performado em 1946, pela SCAP, dois anos após a organização da UEE.

\subsection{A História do Organizar do Salão da SCAP}

A segunda passagem histórica do Salão de Abril ocorre entre dois hiatos de tempo. O primeiro durou dois anos até ser retomada em 1946 sob os auspícios da Scap (Durepos \& Mills, 2017; Estrigas, 1983). Organizada majoritariamente por artistas, a Scap, entre os anos de 1946 a 1958, se alinhou e se mesclou ao Salão de Abril (Silva, 2013). É por meio da atuação e da liderança dessa organização que os atores se realinharam no organizar do Salão, tendo como motivação "elevar o nível cultural artístico da cidade de Fortaleza” (Estrigas, 1994, p. 22). Essa dinâmica de realinhamentos de interesses dos atores em rede evidencia o segundo ponto de oscilação (Durepos \& Mills, 2017). 
Fortalecendo essa organicidade simétrica, além da Scap, outra entidade foi mencionada como ator patrocinador do Salão de Abril: o Clube de Literatura e Arte (Clã) (Bloor, 2009; Estrigas, 1983; Leite, 1949; Será sábado, 1946), evidenciando um múltiplo alinhamento de diferentes interesses em rede. Dois presidentes da Scap estavam ligados ao Clã: Antônio Girão Barroso, em 1947, e Arthur Benevides, em 1954 (Prefeitura de Fortaleza, 1970).

O escritor Antônio Girão Barroso foi um ator que transladou seus interesses da primeira passagem histórica do salão para a segunda, mostrando a organicidade dessa remontagem das redes de atores. Ao contrário da primeira passagem, ele emergiu nessa rede em mais de uma posição, performando uma convergência de interesses diversos. Em 1946, por exemplo, estava à frente do Clã como presidente, discursando na cerimônia de abertura do certame. Já em 1947 atuou como presidente do Clã e da Scap ao mesmo tempo, articulando uma das primeiras associações entre o Salão de Abril e o poder público municipal (Prefeitura de Fortaleza, 1970; Será sábado, 1946) - resquícios históricos indicativos da futura transformação do salão numa política pública de apoio às artes na cidade. Segundo Estrigas (1994), naquele ano, a imprensa ressaltava o apoio do governo do estado ao prometer a medalha ao primeiro lugar do certame, sendo esse o momento em que o poder público atuou pela primeira vez na rede como ator público de fomento do organizar do Salão de Abril.

Após isso, o ator poder público é novamente convergido em rede em 1953. Nesse ano, identificamos também a entrada em campo do ator cidade ao fazer coincidir os períodos de realização do Salão da Scap com o aniversário de Fortaleza. Contudo, tais associações em rede de atores públicos e privados se mantiveram por apenas dois anos. Segundo Estrigas (1994), após o término do mandato do então prefeito, Paulo Cabral de Araújo (1951-1955), a atuação em rede do ator Prefeitura de Fortaleza também cessou. Percebemos que a prefeitura, ator híbrido, se configura na imagem de um ator humano, evidenciando a oscilação híbrida humano - não humano, refletindo um jogo político controverso que atua no organizar do Salão de Abril (Myrick et al., 2013). Analisando esse relato histórico, inferimos que tais versões enfatizaram a tendência de tornar o Salão de Abril uma política pública, realçando nesse debate que os resultados de tais processos dependem de uma complexa interação simétrica entre os diversos grupos de atores envolvidos (Bloor, 2009; Hoffmann et al., 2009; Subirats et al., 2008).

O ano de 1958 foi o último de existência da Scap, coincidindo com o último ano da organização do salão, que entrou em seu segundo hiato de tempo. Mesmo tendo deixado de existir em 1958, as memórias da atuação da Scap ainda persistiram nos relatos das posteriores passagens históricas, como nos catálogos dos anos 1970, 1983, 1996 e 2004. Essa persistência mnemônica se confronta com o primeiro e segundo pontos de oscilação, sobre como o passado se torna história, revelando múltiplas versões, em que alguns atores deixam de atuar, enquanto outros passam a agir como uma rede, e vice-versa (Durepos \& Mills, 2012, 2017).

\subsection{A História do Organizar do Salão (Municipal) da Prefeitura}

Como relatado antes, o ator prefeitura municipal emergiu no Salão da Scap. Após isso, só é transladado no cerne da organização artística a partir de 1964, ano em que o organizar do salão é retomado após um hiato de seis anos. Com o fim da Scap, "os artistas dispersos perderam o contato, mais constante, feito por intermédio da entidade" (Estrigas, 1994, p. 85), enfraquecendo as ações dos atores e suas convergências de interesses em rede. Esses relatos caracterizaram o segundo ponto de oscilação, haja vista que, a partir de 1958, os atores se dispersaram em termos de agir em rede (Durepos \& Mills, 2017).

ReVISTA de Administração Pública ｜ Rio de Janeiro 55(3): 679-696, maio - jun. 2021 
Em 1964, com a atuação de artistas como Zenon Barreto - um dos últimos presidentes da Scap -, João Maria Siqueira, Estrigas e Jean-Pierre Chabloz (Prefeitura de Fortaleza, 1970), os interesses em rede se realinham, visando retomar o organizar do Salão de Abril. Nessa passagem histórica, a reorganização foi fortalecida com o retorno à rede do ator - gestão pública municipal, minimizando seu caráter privado e caracterizando uma formação heterogênea, mas com uma expectativa de um ator - rede pública. Esses relatos performaram a história do salão por meio dessas múltiplas interações não arbitrárias, pública e privada (Bettin \& Mills, 2018; Durepos \& Mills, 2012; Hoffmann et al., 2009; Subirats et al., 2008).

Segundo Estrigas (1994), o catálogo do Salão de 1964 é descrito como “o mais bem elaborado de quantos, até então" (p. 87). Desde 1964, a Prefeitura de Fortaleza é um ator que permanece no cerne do organizar do Salão de Abril até os dias de hoje (Prefeitura de Fortaleza, 2018), evidenciando um alinhamento entre as dimensões privada e pública na gestão da política pública Salão de Abril (Hoffmann et al., 2009; Subirats et al., 2008). O termo "municipal", em algumas edições, passa a fazer parte dos materiais relativos à organização do Salão de Abril, evocando as associações dos interesses da municipalidade nesse processo do organizar artístico do salão (Prefeitura de Fortaleza, 1970). O aniversário de Fortaleza foi mobilizado nos relatos documentais, conforme destacamos:

Art. $1^{\circ}$ - O Salão de Abril é uma mostra de artes visuais, promovida anualmente pela Secretaria de Educação e Cultura do município através do seu Departamento de Cultura, com a finalidade de incentivar, difundir e premiar a capacidade criadora artística, devendo sua abertura realizar-se no dia 13 de abril, em homenagem ao Dia do Município, e encerrar-se no último dia do mesmo mês (Prefeitura de Fortaleza, 1977, p. 2).

A organização artística Salão de Abril passa a integrar oficialmente as atividades do poder público municipal, sendo liderada por atores híbridos humanos e não humanos ligados aos diferentes órgãos da prefeitura, assim como a diferentes associações artísticas (Hoffmann et al., 2009; Subirats et al., 2008). Considerando o quinto ponto de oscilação, foi possível perceber os desafios das associações dos artistas em transladar e alinhar seus controversos interesses no contexto dessa nova rede, com forte conotação pública. Apesar de Hoffmann et al. (2009) e Subirats et al. (2008) terem ressaltado que os resultados desses processos dependem de uma complexa interação entre os diversos grupos de atores envolvidos, traços desses desafios relativos às negociações entre os interesses da política pública Salão de Abril e dos artistas associados não foram resolvidos, sendo estes transladados para a passagem histórica seguinte. Estrigas (1994), por exemplo, comenta que "parte dos artistas, que iam aparecendo a cada Salão, também a cada Salão iam desaparecendo sem deixar maior marca de suas passagens pelo cenário artístico do Ceará” (p. 126).

Como resultado desse processo assimétrico, em 1980, durante o $30^{\circ}$ Salão de Abril, eclode um acontecimento inédito na história por meio do protesto de um grupo de artistas com a criação do I Salão dos Rejeitados, acontecimento que se repetiu em 1985, na 35ª edição, com o Salão dos Recusados. Essas organizações artísticas paralelas à organização oficial da política pública Salão de Abril se inspiraram no Salon des Refusés de 1863, criado por um grupo de jovens pintores franceses que eram tratados com desdém pelo mundo da alta arte parisiense à época. Esses movimentos paralelos à organização oficial do Salão Municipal motivaram alguns atores a criar e a se organizar em novas redes paralelas, performando devires possíveis. 
A partir de 1987, um novo órgão municipal, a Fundação Cultural de Fortaleza (Funcet), emerge nos relatos históricos como responsável pela organização do salão, tendo como presidente Cláudio Pereira, que havia estado à frente do organizar do salão no ano anterior e liderou a fundação por doze anos, até 1998 (Salão de Abril, 1987, 1999). De acordo com Estrigas (1994, p. 179), a política pública Salão de Abril de 1987 conseguiu convergir os interesses do meio artístico. A Funcet permaneceu como órgão organizador do salão até 2007. Em 2008, emergiu a Secretária de Cultura de Fortaleza (Secultfor), que até hoje atua como órgão da prefeitura responsável não só por organizar o Salão de Abril, mas também pela implementação das políticas culturais da cidade de Fortaleza (Salão de Abril, 2018).

A partir dos anos de 2007 e por mais cinco anos, o nome de uma mulher de destacou no cerne da rede pública de atores do salão: Maíra Ortins, que exerceu o papel de curadora geral (Salão de Abril, 2007). É nesse período histórico liderado por Maíra que diferentes espaços, para além dos considerados expositivos, passam a ser articulados no organizar, transformando a narrativa do salão ao colocar os espaços da cidade como atores nesse processo artístico. Em 2008, espaços de Fortaleza como os terminais de ônibus foram inseridos como locais de exposição artística. Em 2009, partes do centro da cidade foram incluídos. Em 2011, práticas artísticas alcançaram o presídio Instituto Penal Professor Olavo Oliveira (Prefeitura de Fortaleza, 2016; Salão de Abril, 2008). Os resultados dessa ampliação espacial do salão, apropriando e, sobretudo, incluindo espaços da cidade, se confirmam nos trechos do catálogo do Salão de Abril (2009, p. 7): "Gerou bons resultados, no que concerne ao alcance dessa produção contemporânea para um público excluído e pouco habituado ao meio artístico visual." Esses movimentos conformaram novas práticas artísticas urbanas que se atualizam nos dias de hoje e que serão relatadas na próxima passagem histórica.

\subsection{A História do Organizar do Salão Sequestrado}

Tendo como base o quarto ponto de oscilação, os relatos propostos para esta quarta e última passagem foram selecionados com base na decisão das autoras-pesquisadoras deste artigo e refletem a relação do pesquisador com os traços do passado e como esses traços estão performando a história (Durepos \& Mills, 2017). Tal decisão se baseou na interpretação de que o passado das associações em rede que incluíram o ator cidade nos processos do organizar da política pública Salão de Abril desencadeou diferentes versões histórias no presente (e futuro?) que atuam(aram) no organizar de espaços da cidade. As versões históricas dessa passagem se relacionam com o organizar do $68^{\circ}$ Salão de Abril Sequestrado e foram baseadas em fontes, como matérias de jornais, mídias sociais e diários de campo, construídos por meio de um específico estudo etnográfico, realizado pela primeira autora deste artigo (Bezerra et al., 2019).

Como um efeito dos desafios evidenciados nas passagens históricas anteriores das complexas negociações entre os atores públicos e os artistas associados, em 2017, emergiu um novo ator à frente do organizar do Salão: o Fórum de Artes Visuais de Fortaleza, liderado em maior parte por artistas e profissionais do setor. A Prefeitura de Fortaleza, por meio da Secultfor, não se pronunciou sobre a realização do $68^{\circ}$ Salão de Abril, confirmando o distanciamento não simétrico entre as diferentes redes de atores públicos e a rede privada (Bloor, 2009; Subirats et al., 2008). Mediante esse distanciamento silencioso e sob a denúncia da ausência de políticas públicas efetivas para a área artística e cultural da cidade, os artistas se fortaleceram em confronto ao poder público ao se 
associar em rede sob os auspícios do fórum, atuando simbolicamente no sequestro da organização do Salão de Abril (Costa, 2017).

Nesse contexto, caracterizamos o movimento do sequestro do organizar do $68^{\circ}$ Salão de Abril (2017) como um retorno renovado das práticas de resistência já ocorridas em 1980 durante o 30 Salão de Abril, com o denominado I Salão dos Rejeitados, e em 1985, na 35ª edição, com o Salão dos Recusados. Além disso, o sequestro foi um efeito que se reverberou de uma ruptura perpetrada por um ator público nos processos do organizar do Salão de Abril, abrindo brechas para a atuação de um ator coletivo, o fórum, convergindo, de forma simétrica, os interesses históricos, políticos e artísticos do setor (Bezerra et al., 2019; Medeiros, 2012; Sousa, 2018; Subirats et al., 2008). Com a palavra, o Fórum de Artes Visuais:

A 68ª Edição do Salão de Abril é uma iniciativa do Fórum de Artes Visuais de Fortaleza que reunidos decidiram o formato do mesmo. Trata-se de uma iniciativa de enfrentamento da ausência de políticas públicas na área da cultura e mais especificamente das artes visuais (Fórum de Artes Visuais, 2017, p. 1).

Além dos atores associados ao fórum, a grande imprensa e as mídias sociais surgem como atores mobilizadores do Sequestro do Salão de Abril, com títulos de editoriais, enfatizando: " $68^{\text {a }}$. Salão de Abril Sequestrado começa hoje, sem apoio da prefeitura" (28/09/2017); "Salão de Abril se espalha pela cidade" (02/10/2017); "Salão de Abril Sequestrado: um pouco de oxigênio" (03/10/2017); "Artistas sequestram Salão de Abril, realizam mostra e criticam ausência de recursos da Prefeitura” (06/10/2017). Observa-se que ocorreu uma associação híbrida que uniu diferentes atores, entre artistas, imprensa e mídias sociais, que se mobilizaram e articularam uma ampla rede organizadora do Salão Sequestrado como um ato de ruptura e resistência à política pública Salão de Abril. As seguintes inscrições atestam esse movimento de resistência e de formação de uma nova rede de atores: "interessados em participar da reunião sobre captação de recursos enviar mensagem in box" ou "existe um grupo no Messenger da equipe envolvida desde o início, onde tem acompanhado o processo do salão" (Diário de campo, set. 2017).

Sob os auspícios do Fórum de Artes Visuais, a organização do Salão Sequestrado ganha destaque, configurando o movimento relacional do terceiro ponto de oscilação, tendo como efeito imediato a ampliação do organizar na urbe, já delineada nas passagens anteriores, mas com a evidente ruptura e resistência à atuação dos atores públicos (Barbalho, 2008; Myrick, Mills \& Mills, 2013).

Particularmente, nesta última passagem, ao contrário do termo "municipal", que foi excluído das narrativas e dos documentos, como evidenciado na análise dos catálogos dessa passagem, as expressões "sequestro", "sequestrar" e "sequestrado", juntamente com "bora sequestrar a cidade?", eram os refrãos do $68^{\circ}$ Salão de Abril, convocando os artistas para ocupar e intervir na cidade por meio da arte (Diário de campo, out. 2017). O organizar do Salão Sequestrado explorou não somente as galerias de arte como espaços expositores, mas 15 diferentes espaços urbanos, incluindo populações que habitam bairros periféricos, nas margens da cidade de Fortaleza. Tais práticas políticas de apropriação e inclusão de espaços urbanos por meio da arte caracterizaram o organizar artístico do Salão de Abril Sequestrado pela atuação dessa nova rede de atores performada pelos artistas associados.

Como já evidenciado, desde o organizar do Salão da Scap entre os anos de 1946 e 1958, surgiram as primeiras inscrições sobre as complexas negociações entre os artistas associados e os organizadores 
públicos do Salão de Abril. Evidencia-se, portanto, um movimento pendular, não cronológico, entre essas múltiplas versões que denotaram existir um passado organizador de resistência e rupturas entre as redes públicas e privadas que performaram, de forma simétrica, a história dessa política pública (Bloor, 2009; Durepos, 2009; Subirats et al., 2008).

Em 2018, a Prefeitura de Fortaleza resgatou o organizar da 69a edição do Salão de Abril. O catálogo da organização da $69^{a}$ edição declara que ela retornou aos auspícios da municipalidade por meio da Secultfor. O catálogo também rompe brevemente o silêncio sobre o organizar do sequestrado ao mencionar que o Salão de 2017 "teve sua realização executada por artistas independentes e sem apoio do Poder Público", chamada "pelos artistas por Salão Sequestrado" (Prefeitura de Fortaleza, 2018, p. 2).

\subsection{Discussão}

Considerando que o conhecimento do passado pode ser (re)montado pelas políticas convergentes (ou não) dos atores em rede, descrevemos no item anterior as 4 passagens históricas identificadas que configuraram o organizar artístico do Salão de Abril de forma pendular e paralela, mas não cronológica.

Tendo como base o quarto e o quinto pontos de oscilações que se referem às decisões do pesquisador em relação aos traços do passado ao gerar diferentes interpretações, observamos que cada uma dessas 4 passagens relatou diversas configurações de uma rede de atores, públicos e privados. Com base no segundo ponto de oscilação que preconiza o alinhamento dos diferentes interesses em rede, evidenciamos que os atores identificados não se posicionavam isolados; ao contrário, misturavam-se e interpolavam-se, oscilando e performando as passagens de forma não cronológica, organizando redes de atores em tempos distintos, mas que se alinhavam (ou não), de forma simétrica, em espaços simultâneos (Durepos \& Mills, 2012; Myrick et al., 2013).

A história do organizar do Salão da UEE evidenciou que a história do Salão de Abril é, desde sua origem, relacional e política (Prefeitura de Fortaleza, 1970). As narrativas relativas à Santíssima Trindade, ao destacarem uma rede de atores heterogêneos, evidenciaram que o processo do organizar do salão estava, desde seus primórdios, baseado nos princípios da simetria, do relacionismo e de uma multiplicidade convergente (ou não) entre os atores, denotando que a trama histórica constrói mais de uma versão do passado, delineando possíveis mundos futuros (Durepos et al., 2012; Hartt et al., 2017; Bettin \& Mills, 2018; Durepos \& Mills, 2017).

A memória da Scap-Clã relacionada às associações com um ator público é mobilizada nas redes subsequentes como um importante ator, evidenciando o primeiro e segundo pontos de oscilação ao performar a história do passado e a refletindo no presente. Tais movimentos pontuaram histórias construídas por controvérsias negociadas e não negociadas, enfatizando um organizar político e artístico, consolidando, de forma assimétrica, o caráter público do Salão de Abril (Bloor, 2009; Durepos \& Mills, 2012; 2017; Estrigas, 1983; Gadelha \& Barbalho, 2017; Myrick et al., 2013; Clark \& Rowlinson, 2004; Decker, 2013).

Entre as 3 últimas passagens históricas analisadas, foram enfatizados os relatos de distanciamentos e aproximações entre os atores relacionados à política pública Salão de Abril e os artistas associados. Nesse interlúdio de tempo, evidenciaram-se diferentes atos de resistências e rupturas capitaneados pelos artistas associados e seus desafios em transladar e alinhar seus controversos interesses em relação aos interesses da rede pública. Esses movimentos assimétricos quanto à organização pública

ReVISTA DE AdMinistração PÚblica ｜ Rio de Janeiro 55(3): 679-696, maio - jun. 2021 
municipal do Salão de Abril motivaram os artistas associados a criar e a se organizar em diferentes redes paralelas, performando devires possíveis ao obscurecer o forte traço público da política Salão de Abril. Tais práticas de resistência e rupturas foram caracterizadas pela eclosão do Salão dos Rejeitados, pelo Salão dos Recusados e, em 2017, pelo Salão Sequestrado.

Esses diferentes desvios históricos que intercalaram as ênfases assimétricas entre as redes pública e/ou privada delinearam criativas negociações no contexto da rede dos artistas associados que, paradoxalmente, atuaram na expansão do organizar da rede de atores do Salão de Abril ao incorporar um novo ator: os espaços da cidade como lugares de exposição artística, incluindo amplas margens da população dos subúrbios. Contudo, no organizar do Salão de Abril de 2018, evidenciou-se o resgate assimétrico da organização pública do salão pela prefeitura da cidade com a renegação da performance organizacional anterior, relacionada tanto às ações de teor político de rupturas e resistências perpetradas pelos artistas associados quanto à apropriação de espaços da cidade como espaços artísticos expositivos.

Esses relatos históricos lançam luzes sobre questões relacionadas aos resultados esperados ao formularmos e implantarmos uma política pública. As políticas dependem da criação e da negociação de um complexo movimento simétrico de envolvimento e interação entre os diferentes interesses dos atores em rede. No contexto da política pública Salão de Abril, essa performance ainda se encontra numa ética e numa estética dos devires (Bloor, 2009; Hoffmann et al., 2009; Subirats et al., 2008).

\section{CONSIDERAÇÕES FINAIS}

Com base nos relatos construídos entre as passagens históricas que caracterizaram a história do Salão de Abril, diversos contextos de um organizar artístico foram performados por meio da (des) mobilização de diferentes redes de atores, público e privado, que convergiram (ou não) no tempo e no espaço.

As múltiplas práticas relacionais perpetradas pelos artistas associados ao divergirem do ator rede pública provocou o alastramento de um organizar artístico assimétrico que se apropriou de espaços da cidade. No tempo presente, paradoxalmente, esse organizar assimétrico do Salão Sequestrado, ao romper com os atores públicos, deu voz as redes dos artistas associados que, em tempos passados, se pronunciaram em busca de fomento, participação e, sobretudo, democratização das políticas públicas artísticas, no sentido de tornarem a cidade a própria terra prometida por meio da arte.

Esta discussão indica uma importante contribuição deste estudo ao evidenciar as práticas de resistências e rupturas que conotaram significados para a renovação de políticas públicas inclusivas e da necessidade de (trans)formação do organizar artístico dos Salões de Abril. Reconhecer os meandros do apelo político inclusivo ao se distanciar de uma prática artística enclausurada nas galerias de arte, ocupando amplos espaços dos subúrbios da cidade, torna-se uma discussão reveladora para fomentar a formulação de políticas públicas criativas para o setor.

Enfatiza-se ainda a contribuição deste artigo no sentido de avanços teóricos no contexto dos estudos organizacionais, mais especificamente, nas articulações dos temas das organizações artísticas, da política pública e da história. Consideramos que o organizar da política pública Salão de Abril, da forma como entendemos e atuamos hoje, é o resultado de uma construção histórica, permeada por desvios, silêncios e paradoxos. Os percursos históricos revelados foram (trans)formados ao longo do tempo e se manifestaram por meio de relatos, por vezes silenciados, articulando diferentes temporalidades em espaços simultâneos. 
Tais discussões problematizaram a história da política pública Salão de Abril como um nexo conector entre as redes de atores, performando a capacidade de alterar a dinâmica das formulações das políticas públicas (pre)existentes. O passado não desaparece, mas se transforma ao persistir na sua evocação mnemônica, atuando no tempo presente e se abrindo para o futuro. Assim, buscamos, como contribuição primeira, estimular uma ampliação da compreensão das políticas públicas no organizar artístico com base numa visão histórica, em que seja possível vislumbrar a natureza relacional, múltiplas e simétrica entre tempos e espaços. 


\section{REFERÊNCIAS}

Barros, A. (2016). Archives and the "Archive": Dialogue and an agenda of research in organization studies. Organizações \& Sociedade, 23(79), 609-623.

Barros, A., Alcadipani, R., \& Bertero, C. O. (2018). A criação do curso superior em administração na UFRGS em 1963: uma análise histórica. RAE Revista de Administração de Empresas, 58(1), 3-15.

Bettin, C., \& Mills, A. (2018). More than a feminist: ANTi-Historical reflections on Simone de Beauvoir. Management \& Organizational History, 13(1), 65-85.

Bezerra, M. M., Lopes, L. L. S. da Silva, J. S., \& Ipiranga, A. S. R. (2019). Spatial practices in the city: The Kidnapping of an Arts Organization. Brazilian Administration Review, 16(4), 1-23.

Bloor, D. (2009). Conhecimento e imaginário social. São Paulo, SP: Enesp.

Booth, C., \& Rowlinson, M. (2006). Management and organizational history: Prospects. Management and Organizational History, 1(1), 5-30.

Clark, P., \& Rowlinson, M. (2004). The treatment of history in organization studies: Towards an 'historic turn'? Business History, 46(3) 331-352.

Cooper, R. (1976). The Open Field. Human Relations, 29(11), 999-1017.

Corrigan, L. (2019). Accounting Narratives: The Presentation of History in Budget Making. In C. Hartt (Ed.), Connecting Values to Action: NonCorporeal Actants and Choice. Bingley, UK: Emerald Publishing Limited.

Costa, I. (2017). Esperando setembro chegar... O Povo. Recuperado de https://www.opovo.com.br/ jornal/vidaearte/

D’Astous, A., Colbert, F., \& Fournier, M. (2007). An experimental investigation of the use of brand extension and co-branding strategies in the arts. Journal of Services Marketing, 21(4), 231-240.

Deal, N., Mills, A., Mills, J., \& Durepos, G. (2019). History in the Making: Following the Failed Attempt of Wolfgang Langewiesche in Pan American Airways History Project. In C. Hartt (Ed.), Connecting Values to Action: Non-Corporeal Actants and Choice. Bingley, UK: Emerald Publishing Limited.
Decker, S. (2013). The silence of the archives: Business history, post-colonialism and archival ethnography. Management \& Organizational History, 8(2), 155-173.

Durepos, G. (2009). ANTi-History: Toward an Historiographical Approach to (Re)assembling Knowledge of the Past (Ph.D. Dissertation). Saint Mary's University, Halifax, CA. Recuperado de http://www.springerlink.com.library2.smu.ca/ handle/01/17512\#.XQ50ffZFw2w

Durepos, G., \& Mills, A. (2012). Actor network theory, ANTi-History, and critical organizational historiography. Organization, 19(6), 703-721.

Durepos, G., \& Mills, A. (2017). ANTi-History, relationalism and the historic turn in management and organization studies. Qualitative Research in Organizations and Management - An International Journal, 12(1), 53-67.

Durepos, G., Mills, A., \& Weatherbee, T. G. (2012). Theorizing the past: Realism, relativism, relationalism and the reassembly of Weber. Management \& Organizational History, 7(3), 267-281.

Estrigas, N. F. (1983). A fase renovadora na arte cearense. Fortaleza, CE: Edições Universidade Federal do Ceará.

Estrigas, N. F. (1994). O Salão de Abril. Fortaleza, CE: Edições Fundação Cultural de Fortaleza.

Exposição de arte e pintura da U.E.E. (1943, março 29). O Povo, Fortaleza, p. 4, Arquivo de Microfilmagem, Biblioteca Pública do Estado do Ceará, Fortaleza, CE.

Festivamente comemorado em Fortaleza o dia do presidente (1943, abril 19). O Povo, Fortaleza, p. 4, Arquivo de Microfilmagem, Biblioteca Pública do Estado do Ceará, Fortaleza, CE.

Flach, L., \& Antonello, C. S. (2011). Organizações culturais e a aprendizagem baseada em práticas. Cadernos EBAPE.BR, 9(1), 156-176. Recuperado de http://www.scielo.br/pdf/cebape/v9n1/v9n1a10

Fórum de Artes Visuais. (2017). Convocatória de artistas para o $68^{\circ}$ Salão de Abril Sequestrado. Recuperado de https://www.facebook. com/68SalaodeAbrilSequestrado/

Gadelha, R., \& Barbalho, A. (2017). Política e produção cultural no Ceará (1960-2014): a formação 
de um campo. Estudos de Sociologia, 1(23), 53-86. Recuperado de https://periodicos.ufpe.br/revistas/ revsocio/article/view/235792

Grey, C. (2010). Um livro bom, pequeno e acessivel sobre os estudos organizacionais. Porto Alegre, RS: Bookman.

Hartt, C., Mills, A., Mills, J. H., \& Corrigan, L. T. (2014). Sense-making and actor networks: the noncorporeal actant and the making of an Air Canada history. Management \&Organizational History, 9(3), 288-304.

Hartt, C., Mills, J. H., Mills, A., \& Durepos, G. (2017), Performing the past: ANTi-History, gendered spaces, and feminist practice. In A. Mills (Ed.), Insights and research on the study of gender and intersectionality in international airline cultures. Bingley, UK: Emerald Publishing Limited. Recuperado de https://www. emeraldinsight.com/doi/book

Hoffmann, S., Silva, F., \& Dellagnelo, E. (2009). Objetivos de organizações culturais sem fins lucrativos e suas fontes financiadoras. Cadernos EBAPE.BR, 7(2), 183-198.

Ipiranga, A. S. R. (2010). A cultura da cidade e os seus espaços intermediários: os bares e os restaurantes. RAM - Revista de Administração Mackenzie, 11(1), 65-91.

Ipiranga, A. S. R., Chaym, C. D., \& Sousa, F. G. P. (2016). Relatos sobre o organizar do sócio-passado em uma patente brasileira de biotecnologia. Revista Eletrônica de Ciência Administrativa, 15(2), 133-147.

Kieser, A. (1994). Why organization theory needs historical analyses-and how this should be performed. Organization Science, 5(4), 608-620.

Kivijärvi, M., Mills, A., \& Mills, J. H. (2019). Performing Pan American Airways through coloniality: An ANTi-History approach to narratives and business history. Management \& Organizational History, 1(1), 1-22.

Latour, B. (2012). Reagregando o social: uma introdução à teoria do ator-rede. Salvador, BA: Edufba.

Law, J. (1992). Notes on the theory of the actornetwork: ordering, strategy, and heterogeneity. Systems Practice, 5(4), 379-393.

Leite, B. (1949). Esquema da pintura do Ceará. Fortaleza, CE: Edições Clã.

Maxqda. (2018). Computer software. Recuperado de https://www.maxqda.com/
Medeiros, J. (2012). Onde experimentar? Políticas Culturais em Revista, 5(2), 151-163.

Myrick, K., Mills, J. H., \& Mills, A. (2013). Historymaking and the Academy of Management: An ANTiHistory perspective. Management \& Organizational History, 8(4), 345-370.

Prefeitura de Fortaleza. (1968). Catálogo da $18^{a}$ edição. Fortaleza, CE: Secretaria de Cultura Municipal de Fortaleza. Recuperado de http://www. salaodeabril.com.br

Prefeitura de Fortaleza. (1970). Catálogo da $20^{a}$ edição. Fortaleza, CE: Secretaria de Cultura Municipal de Fortaleza. Recuperado de http://www. salaodeabril.com.br

Prefeitura de Fortaleza. (1977). Catálogo da $27^{a}$ edição. Fortaleza, CE: Secretaria de Cultura Municipal de Fortaleza. Recuperado de http://www. salaodeabril.com.br

Prefeitura de Fortaleza. (1996). Catálogo da $47^{a}$ edição. Fortaleza, CE: Secretaria de Cultura Municipal de Fortaleza. Recuperado de http://www. salaodeabril.com.br

Prefeitura de Fortaleza. (2011). Catálogo da $62^{a}$ edição. Fortaleza, CE: Secretaria de Cultura Municipal de Fortaleza. Recuperado de http://www. salaodeabril.com.br

Prefeitura de Fortaleza. (2016). Salão de Abril Mapeamento dos lugares de realização. Recuperado de http://www.salaodeabril.com.br

Prefeitura de Fortaleza. (2018). Catálogo da 69a edição. Fortaleza, CE: Secretaria de Cultura Municipal de Fortaleza. Recuperado de http://www. salaodeabril.com.br

Quelha-de-Sá, R. G., \& Costa, A. D. S. M. (2018). ANTi-History e a pesquisa em administração: Reflexões iniciais. Cadernos de Gestão e Empreendedorismo, 6(1), 46-58.

Reis, A. C. F. (2007). Economia da cultura e desenvolvimento sustentável. São Paulo, SP: Manole.

Rentschler, R., \& Potter, B. (1996). Accountability versus artistic development: the case for non-profit museums and performing arts organizations. Accounting, auditing \& accountability journal, 9(5), 100-113. 
Schwartz, J. M., \& Cook, T. (2002). Archives, records, and power: The making of modern memory. Archival science, 2(1-2), 1-19.

Será sábado próximo a inauguração do segundo Salão de Abril (1946, abril 23). Unitário, Arquivo de Microfilmagem, Biblioteca Pública do Estado do Ceará, Fortaleza, CE.

Silva, A. (2013). Os Salões de Abril e os grupos SCAP e CLÃ como espaços de sociabilidade. Revista de História Bilros - História (s), Sociedade (s) e Cultura (s), 1(1), 57-72. Recuperado de http://seer.uece. br/?journal=bilros

Sousa, F. H. R. (2018). Salão Sequestrado na História do Salão de Abril. In Anais do $27^{\circ}$ Encontro da Associação Nacional de Pesquisadores em Artes Plásticas, São Paulo, SP.
Strati, A. (1995). Aesthetics and organizations without walls. Studies in Cultures, Organizations and Societies, 1(1), 83-105.

Subirats, J., Knoepfel, P., Larrue, C., \& Varone, F. (2008). Análisis y gestión de políticas públicas. Barcelona, España: Ariel.

Vieira, M. M. F., Knopp, G., \& Costa, M. (2011). Culture as educational intervention for change: the experience of the Neighbourhood-School Programme in the city of Nova Iguaçu, Brazil. City, Culture and Society, 2(1), 17-24.

Vizeu, F. (2010). Potencialidades da análise histórica nos estudos organizacionais brasileiros. RAE Revista de Administração de Empresas, 50(1), 36-46. Recuperado de http://bibliotecadigital.fgv.br/ojs/ index.php/rae/article/view

\section{Mariana Maia Bezerra}

https://orcid.org/0000-0002-9217-0052

Mestre em Administração pela Universidade Estadual do Ceará; Professora universitária da Faculdade de Ciências e Tecnologia do Nordeste. E-mail: marianamaiab7@gmail.com

\section{Ana Sílvia Rocha Ipiranga}

https://orcid.org/0000- 0001-8095-6800

Doutora em Psicologia do Trabalho e Organizacional pela Universidade de Bologna (Itália); Pós-Doutora em Administração pela Escola Brasileira de Administração Pública e de Empresas da Fundação Getulio Vargas (FGV EBAPE); Professora Associada do Programa de Pós-Graduação em Administração da Universidade Estadual do Ceará. E-mail: silvia.ipiranga@uece.br 